\title{
A Importância da Generosidade no Início da Gênese da Moralidade na Criança
}

\section{The Importance of Generosity at the Begining of Moral Development in Childhood}

\author{
Yves de La Taille* \\ Universidade de São Paulo
}

\begin{abstract}
Resumo
No presente artigo, apresentamos uma análise do papel da generosidade no universo moral da criança. Começamos por definir a generosidade enquanto virtude moral, comparando-a com a justiça. Em seguida, fazemos uma revisão da literatura psicológica que nos traz dados sobre elementos relacionados a ela (ética do cuidado, atitudes pró-sociais e simpatia) e apresentamos a hipótese segundo a qual a generosidade é melhor assimilada do que a justiça por parte de crianças de 6 anos. Para testar esta hipótese, apresentamos os resultados de 2 pesquisas com crianças de 6 e 9 anos, nas quais pedimo-lhes que atribuem sentimentos a personagens não justas e não generosas. Coerentemente com resultados de estudos anteriores, a maioria das crianças de 6 anos atribui sentimentos positivos à personagem não justa. Em compensação, elas atribuem sentimentos negativos às personagens não generosas. Estes dados são discutidos para defender a hipótese segundo a qual a generosidade, por ser menos dependente de regras e imposições adultas, tem raízes mais profundas do que a justiça na consciência moral infantil.

Palavras-chave: Moral; generosidade; justiça; desenvolvimento.
\end{abstract}

\begin{abstract}
In the present research, we analyse the role of generosity in the moral universe of childhood. We begin by defining generosity as a moral virtue, comparing it with justice. Then, we present a literature review of generosity-related psychological elements (ethics of care, pro-social attitudes, sympathy) and establish the hypothesis that this virtue is better understood than justice by subjects who are six and nine years of age. To test this hypothesis, we present the results of two empirical studies with 6 and 9 year old children, in which we asked that they attribute feelings to people acting unjustly and ungenerously. While we confirm previous studies showing that six year olds have the tendency to attribute positive feelings to unjust people, the results show that negative feelings are attributed to ungenerous people. The discussion of this data defends the hypothesis according to which generosity, being less dependent of adult rules and impositions, has deeper roots than justice in the child's moral conscience.

Keywords: Moral; generosity; justice; development.
\end{abstract}

O presente artigo apresenta reflexões e duas pesquisas sobre o papel e importância da virtude generosidade no desenvolvimento moral, notadamente na fase do despertar do senso moral (Tugendhat, 1998), ou seja, no início da gênese da moralidade na criança. Começaremos por definir o que é generosidade, comparando-a a esta outra virtude essencial à moral que é a justiça, objeto da grande maioria das pesquisas. Em seguida, retomando algumas teorias de Psicologia Moral, analisaremos a possível presença da generosidade no universo moral das crianças pequenas, fazendo a hipótese de que não somente esta presença é real como tem raízes mais profundas, na consciência infantil, do que a justiça. Para dar verossimilhança a esta hipótese e justificar o método de pesquisa empregado, abordaremos o

Colaboradoras: Eliana Cristina Bulgarelli, Fernanda Coppeli Vilas Boas de Almeida, Helena Amstalden Imanischi e Prislaine Krodi dos Santos. Financiamento: Fapesp e Cnpq.

* Endereço: IP-USP, Av. Prof.Mello Moraes, 72 1,05508900,São Paulo,SP.ytaille@uol.com.br tema dos sentimentos morais, notadamente no que tange às pesquisas sobre o 'feliz vitimizador' (happy victimiser). Procuraremos mostrar que, se nossa hipótese for correta, as crianças que atribuem sentimentos positivos a alguém que infringe uma regra de justiça não fazem mesma atribuição quando se trata de uma ação não generosa. Após estas considerações de ordem teórica, apresentaremos as pesquisas e analisaremos os dados encontrados.

\section{A Generosidade}

O Dicionário Houaiss assim define generosidade: “virtude daquele que se dispõe a sacrificar próprios interesses em benefício de outrem”. Outros dicionários (Aurélio, Lexis) dão, grosso modo, a mesma de definição e colocam como sinônimas outras virtudes, que se encontram em diversos filósofos: magnanimidade (Aristóteles, 1965), caridade (teologia cristã), benevolência (Spaemann, 1997), entre outros. 
Três aspectos da generosidade devem ser sublinhados, pois, como veremos, singularizam-na em relação à justiça. $\mathrm{O}$ primeiro é o altruísmo: no ato generoso, é outrem que é o beneficiário da ação. O segundo: na generosidade há um sacrifício, ou seja, um 'dom de si', para retomar a expressão de Comte-Sponville (1995). O terceiro aspecto: na generosidade, dá-se a outrem, não o que lhe cabe de direito, mas sim o que corresponde a uma necessidade singular.

Isto posto, não parece levantar dúvidas a afirmação de que a generosidade é uma virtude pertencente ao campo moral. Com efeito, vêmo-la tratada e admirada por filósofos da Ética como Aristóteles (s.d./1965), Adam Smith (1723/ 1999), Kant (1785/1994), Schopenhauer (1840/1995), e, mais perto de nós, Spaemann (1997), Tugendhat (1998), MacIntyre, (1997), Savater, (2000), Flanagan (1996). Todo o problema filosófico reside em situá-la, no campo da moral, e todo problema psicológico consiste em saber se desempenha algum papel, e qual, na formação do sujeito moral.

Como nosso objetivo não é o de escrever um texto de axiologia, limitamo-nos em sublinhar o fato de que, nos debates filosóficos, as reflexões sobre a generosidade quase sempre visam situá-la em relação à justiça. Para alguns, a justiça ocupa o topo da hierarquia das virtudes morais. É o caso de Aristóteles, que a ela deu destaque por ser virtude completa porque sempre boa. Também é o caso de Adam Smith, que dedicou todo um capítulo de seu célebre texto dedicado à análise dos sentimentos morais a tal comparação (ele emprega o conceito de benevolência). Ele observava que a falta da generosidade não é sancionada por nenhum castigo enquanto o ato injusto recebe tal sanção. Segundo ele, isto se deve ao fato de que, enquanto a ausência de generosidade não acarreta, por ela mesma, nenhum mal positivo, o ato injusto traz um mal à pessoa injustiçada. Em poucas palavras, enquanto a generosidade é esperada, a justiça é exigida. No que diz respeito à importância humana e social de ambas as virtudes, o filósofo pondera que a benevolência é menos essencial à existência da sociedade do que a justiça. A sociedade pode manterse sem benevolência, embora num estado não confortável; mas a predominância da injustiça a destruirá absolutamente (1999, p.141). Para outros autores, ou a generosidade é virtude superior (Schopenhauer, 1840/1995) ou, pelo menos, tão importante quanto a justiça (Flanagan, 1996; Gilligan, 1982; MacIntyre, 1997; Ricoeur, 1990). Como veremos a seguir, reencontramos a mesma discussão no campo da psicologia moral, embora o conceito de generosidade seja nele pouco empregado (fala-se em 'cuidado', 'simpatia' ou atitudes 'prósociais'). Mas antes, vamos detalhar as três diferenças básicas que diferenciam generosidade de justiça.

Em primeiro lugar, dissemos que a generosidade é intrinsecamente altruísta. É claro que, sendo a justiça uma tradução de uma preocupação com o outro, ela também pode figurar entre as virtudes altruístas. Porém, este fato não deve nos impedir de notar dois aspectos essenciais que separam justiça da generosidade. O primeiro é o fato de a justiça poder ser objeto legítimo de reivindicação pessoal, no sentido que uma pessoa exigir ser tratada de forma justa.
É evidente que, neste caso, não se trata de atitude altruísta, mas este fato em nada amputa sua legitimidade moral. Ora, o mesmo não acontece com a generosidade, pois ninguém pode, com legitimidade, exigir ser tratado de forma generosa, somente pode desejá-lo. Em suma, a generosidade é sempre genuinamente altruísta, a justiça não. O segundo aspecto é o fato de a justiça sempre visar o bem comum,portanto, também o da pessoa que age de forma justa. Por exemplo, se uma pessoa de cor branca denuncia a discriminação racial contra os negros, ela está, obviamente, preocupando-se com outrempois ela não sofre tal discriminação - mas, ao mesmo tempo, está exigindo um regra justa que também a beneficia - nem brancos, nem negros devem ser discriminados. Em resumo, o auto-interesse, ao lado do interesse pelo outro, está sempre presente na justiça, mas não no caso da generosidade, pois nela apenas o interesse pelo outro está em jogo.

Em segundo lugar, afirmamos que a generosidade pressupõe um sacrifício, ou um 'dom de si'. Ser justo não implica necessariamente em privação. Dizemos não necessariamente por há casos em que as ações inspiradas pela justiça implicam, de fato, abnegação. É o caso de algumas formas de solidariedade nas quais uma pessoa luta para que a justiça social se torne realidade para grupos aos quais não pertence. Neste casos, há, de fato, um 'dom de si’ (do tempo gasto na militância até, dependendo do regime político vigente, o risco de perder a vida). Porém, quando uma pessoa age de forma justa, portanto respeita um direito alheio, não há real 'dom de si', mas sim o estrito cumprimento do dever.

A dimensão do direito, decorrente do conceito de justiça baseado na igualdade e na eqüidade, corresponde à terceira diferença entre ela e a generosidade. No ato generoso dá-se a outrem o que corresponde a uma necessidade singular, e não a um direito. Em outras palavras, enquanto a justiça considera o 'sujeito de direito', portanto, 'todos os seres humanos', a generosidade contempla o 'sujeito singular', portanto, outrem na sua concretude (ver Ricoeur, 1990).

Isto posto, vamos agora ver o que a Psicologia Moral tem a nos dizer sobre generosidade.

\section{Generosidade e Psicologia Moral}

O mínimo que se pode afirmar é que a virtude generosidade não tem inspirado pesquisas psicológicas. É pelo menos o que nossa revisão bibliográfica mostrou. No Brasil, Dias (2002), Tognetta (2003) e Lima (2003) realizaram trabalhos nos quais explicitam a referida virtude. No exterior, não encontramos trabalhos que coloquem a generosidade como foco das investigações. Em compensação, há reflexões e pesquisas que, embora não incidam nominalmente sobre esta virtude, não lhe são estranhas. É o caso dos trabalhos sobre ética do cuidado, sobre condutas pró-sociais e sobre simpatia (ou empatia).

É sabido que Carol Gilligan (1982) causou um certo abalo, na Psicologia Moral, contestando a abordagem teórica inaugurada por Piaget (1932/1992), seguida e ampliada por Kohlberg (1981). Duas são suas teses centrais. A primeira: haveria diferenças de gênero nas formas de se 
conceber a vida moral. A segunda: haveria não apenas a ética da justiça, mas também outra, a ética do cuidado, esta mais desenvolvida pelas mulheres. No contex to do presente trabalho, apenas a segunda tese nos interessa, pois, embora não fale em generosidade, a ética do cuidado a contempla. Com efeito, quando Gilligan afirma que tal ética corresponde a «uma voz que fala de conexão, de não ferir, de cuidar, de corresponder' (1988, p.8), verifica-se que ela pensa em ações que levam em conta as necessidades alheias. Quanto aos direitos alheios, sua definição de ética da justiça a coloca como uma voz fala de igualdade, reciprocidade, justiça e direitos (1988, p.8). Encontramos, portanto, nos trabalhos de Gilligan um abordagem que, se não se restringe à generosidade, pelo menos abre um campo de reflexões no qual ela tem lugar. Dizemos que ela não se restringe à generosidade porque a ética do cuidado também remete a dimensões morais outras, como a riqueza das relações interpessoais, e por conseguinte, poderia abarcar outras virtudes, como a fidelidade e a gratidão (ver La Taille, 2002c). Todavia, devemos ressaltar o fato de a abordagem de Gilligan permitir pensar a generosidade enquanto virtude moral relevante, relevância esta afirmada no presente artigo. Todavia, como nossa intenção não é a de, como referido acima, colocar a generosidade em hierarquia igual à da justiça, mas sim avaliar sua importância na gênese da moralidade, as hipóteses genéticas de Gilligan pouco nos ajudam nesta empreitada, pois estão intimamente relacionadas a diferenças de gênero na qualidade da relação filho(a)/mãe.

Outra abordagem teórica que abre espaço para reflexões e pesquisas sobre generosidade, embora também não se refira a ela, é aquela que responde pelo nome de estudo de 'atitudes pró-sociais' (ver Eisenberg-Berg, 1979, Eisenberg \& Lennon, 1983, Kahn, 1992). Enquanto Gilligan procurou deslocar o eixo das pesquisas da justiça para o cuidado, tal abordagem, que tem na figura de Eisenberg sua principal autora, traz a oposição entre deveres negativos e deveres positivos. Esta oposição também configura uma solução de continuidade em relação aos trabalhos de Piaget e Kohlberg. Conflitos interpessoais e transgressões a regras, eis os temas que os dois autores incessantemente trazem nas entrevistas clínicas que realizaram com seus sujeitos. Ajudar a quem precisa, eis o tema central dos estudos sobre condutas chamadas de pró-sociais. Embora não restritas à generosidade, tais atitudes compartilham pelos menos quatro características com esta virtude.

A primeira diz respeito às regras. Sabe-se que Piaget (1932/1992) definiu a moral com um conjunto de regras, mas tal definição está longe de fazer unanimidade entre os filósofos da Ética, como o demonstra a leitura de autores como Flanagan (1996), Tugendhat (1998), MacIntyre (1997) e Ricoeur (1990), entre outros. Este debate gira em torno da oposição entre deveres negativos e positivos. Para os primeiros, há regras, mas nem sempre para os segundos. Ora, a generosidade, assim como outras atitudes pró-sociais, consiste, evidentemente, em um dever positivo.
Porém, pode-se dizer que a generosidade consiste num dever? Esta pergunta corresponde à segunda característica que queremos destacar. Para respondê-la é preciso fazer a diferença entre o sentimento pessoal de obrigatoriedade e a exigibilidade social. No caso dos deveres negativos (como não matar, não mentir, não roubar), a sociedade exige de seus membros sua obediência, e pune a desobediência. Tal não costuma acontecer para os deveres positivos: eles são admirados, esperados, desejados, mas não exigidos. Vimos acima que Smith aponta para esta característica de não exigibilidade da generosidade. $\mathrm{O}$ sentimento pessoal do dever moral não coincide com a exigibilidade exterior, pois se traduz por um 'querer fazer', por uma 'vontade boa', para empregar um termo kantiano. Prosseguindo com este autor, é moral aquilo que se faz 'por dever' e não apenas 'conforme o dever'. Ora, assim definido, o sentimento pessoal de dever pode tanto incidir sobre condutas passíveis de exigência social quanto para aquelas não regidas por leis. Assim, a generosidade, embora não exigida socialmente, pode mesmo assim corresponder, para determinadas pessoas, a um dever moral.

A terceira característica das atitudes pró-sociais e, logo, da generosidade, é sua tênue relação com a autoridade. Trata-se agora, não de uma análise axiológica, mas sim psicológica, atinente à educação moral. Eisenberg sugere que, nas prescrições morais que os adultos fazem às crianças, as atitudes pró-sociais ficam em segundo plano, atrás das regras que traduzem os deveres negativos. Não conhecemos pesquisa que ateste este fato, mas o bom senso parece comprová-lo. Sendo as atitudes pró-sociais, entre elas a generosidade, menos relacionadas com as ordens advindas de autoridade, elas devem ser mais 'espontâneas' nas crianças menores e, acrescentaríamos, mais autônomas. Esta é a tese de Eisenberg (1993), que, como veremos abaixo, nos ajuda a formular a hipótese de que a generosidade cumpre papel no desenvolvimento moral. Mas de onde viria a precocidade do valor atribuído às condutas pró-sociais e sua relativa independência em relação à autoridade? Alguns autores pensam encontrar a resposta na capacidade de simpatia (ou empatia).

Além dos trabalhos com a ética do cuidado e com as condutas pró-sociais, aqueles realizados sobre a simpatia (ou empatia) não são estranhos às reflexões sobre generosidade. Eisenberg diferencia empatia de simpatia, definindo a primeira como estado emocional proveniente da apreensão do estado emocional de outra pessoa, e que é congruente com este (Eisenberg, 1987, p.91), e a segunda como resposta emocional proveniente do estado emocional de outra pessoa, que não é idêntico a tal estado, mas consiste em sentimentos de pena ou interesse pelo bem-estar de outrem (pp.91-92). Esta diferenciação entre os dois conceitos não faz unanimidade. Adam Smith limita-se a empregar o conceito de simpatia definido como afinidade com toda paixão' (1723/1999, p.27), definição esta mais próxima daquela dada por Eisenberg à empatia. Tal proximidade também encontra-se no Dicionário Houais, no qual simpatia é definida como faculdade de compenetrar-se das idéias ou 
sentimentos de outrem e também nos trabalhos de Hoffman (1978).

A despeito da preferência por um conceito ou outro, e também a despeito das nuanças que separam definições, o essencial é sublinhar que simpatia e empatia designam a capacidade humana de perceber os estados emotivos de outrem e se afetar emocionalmente por eles. Dito de outra forma, ambos os conceitos dizem respeito a um 'operador emocional', passível de motivar uma pessoa a preocupar-se com outrem. Daí sua íntima relação com a moral, notadamente com o altruísmo. Adam Smith, por exemplo, conduz sua reflexão moral a partir do conceito de simpatia, e Schopenhaeur elege a compaixão (simpatia no caso da dor alheia) como fonte de todas as ações justas e caridosas. $\mathrm{Na}$ área da Psicologia Moral, encontramos a relação entre empatia e condutas pró-sociais- embora esta relação não esteja, segundo a revisão feita por Eisenberg (1987), claramente estabelecida em razão da grande variação de métodos por intermédio dos quais se mede a empatia. Do ponto de vista do desenvolvimento, Hoffman afirma que $a$ empatia ocorre muito antes que os controles morais da criança estejam firmemente estabelecidos (Hoffman, 1978, p.123). Note-se que Piaget (1954) também recorreu ao conceito de simpatia para analisar a dimensão afetiva do desenvolvimento moral, definindo-a como sentimento fonte de atribuição de valor positivo a outrem em razão de suas ações (seu contrário é a antipatia). A simpatia participaria, portanto, do jogo das valorizações mútuas que dirige a criança ao respeito mútuo.

No que tange à relação entre generosidade e simpatia (ou empatia), ela é clara, uma vez que o exercício da referida virtude pressupõe perceber-se a necessidade singular de uma determinada pessoa (ou grupo de pessoas), e contemplála por intermédio de um 'dom de si’. Uma pessoa por ventura incapaz de simpatia talvez nem percebesse a necessidade alheia, certamente não se comoveria com ela, e, por conseguinte, não agiria de forma generosa.

\section{Hipóteses da Pesquisa}

Após termos verificado a relevância axiológica da generosidade (item 1) e a existência de pesquisas e abordagens teóricas em Psicologia Moral que a contemplem, nem que seja indiretamente (item 2), devemos agora a apresentar as idéias mestras que dão base à nossas hipóteses e à nossa pesquisa. Vamos fazê-lo em quatro momentos sucessivos e complementares: 1) no início da gênese da moral, nem tudo é relação com autoridade, hedonismo instrumental e medo do castigo; 2) a generosidade é virtude presente no início da gênese da moralidade; 3) ela é melhor assimilada e, portanto, integrada à consciência moral do que a justiça; $\mathrm{e}$ 4) tal integração deve traduzir-se por uma resposta emocional superior àquela relacionada à justiça. Vamos explicitar as quatro afirmações:

a) No seu texto fundador da Psicologia Moral, Piaget (1932/1992) consagrou a idéia segundo a qual há duas morais, uma da coação, outra da cooperação, sendo a última superação genética da primeira. A moral da coação, também chamada de moral heterônoma (ou heteronômica), traduz- se essencialmente pelo respeito unilateral pelas ordens de figuras de autoridade. Trata-se, portanto, de uma moral da obediência, obediência esta motivada pela fusão dos sentimentos de amor e medo experimentados pela criança pequena em relação a seus pais e demais figuras adultas afetivamente significativas de seu entorno. Verifica-se que, nesta concepção teórica, há pouco espaço para pensar que existam, no universo moral da criança, regras e virtudes outras que aquelas coercitivamente impostas pelos adultos. Veremos logo abaixo que Piaget, em alguns trechos de seu livro Le Jugement Moral Chez l'Enfant (1932/1992), sugere que a vida moral da criança é mais rica e mais complexa, mas o fato é que tal dependência da autoridade configura o eixo de sua interpretação da consciência moral infantil. Isto se deve ao fato de Piaget, em toda sua obra, sempre sacrificar o estudo da complexidade do 'sujeito psicológico' à identificação das estruturas universais do 'sujeito epistêmico', ou do 'sujeito ético'. Com efeito, no caso do desenvolvimento do juízo moral, não importava tanto a Piaget descrever a riqueza do mundo moral infantil, mas sim identificar o fio condutor do desenvolvimento subseqüente, a saber, o a progressiva superação da heteronomia pela autonomia.

Kohlberg, como se sabe, inspirou-se em Piaget, ao buscar identificar no progressivo desenvolvimento da reversibilidade o fio condutor do desenvolvimento moral. Ele assim define o primeiro estágio da gênese da moralidade, o nível pré-convencional:

Neste nível, a criança responde a regra culturais e rótulos de bom e ruim, de certo e errado, mas interpreta tais rótulos em termos conseqüência, sejam físicas ou hedonísticas da ação (punição, recompensa, troca de favores), ou em termos da força física de quem enuncia as regras e rótulos. (Kohlberg, 1981, pp.17-19)

Kohlberg guarda de Piaget a referência à autoridade (embora ressaltando mais do que ele o medo da puniçãoneste sentido ficando mais próximo de Freud (1991) para a descrição da primeira etapa do desenvolvimento moral), mas também coloca a dimensão do hedonismo, pouco enfatizada pelo psicólogo suíço.

Verifica-se que, na interpretação destes dois autores, principais figuras das teorias de desenvolvimento moral, para a criança menor, seria moral aquilo que corresponde à obediência, seja ela motivada pela autoridade ou pela correlação de forças. Todavia, tal interpretação tem sido contestada. Eis o que pondera Tugendhat:

O respeito moral somente pode desenvolver-se em todas as suas sutilezas, no seio de relações estreitas, e ele é essencial a estas relações. Portanto, podemos tomar como pouco convincente a tese defendida por Piaget no Le Jugement Moral chez l'Enfant, segundo a qual as crianças somente desenvolvem um respeito unilateral em relação a seus pais - respeito que Piaget concebe como uma mistura de medo e amor, o que implica uma atitude pré-moral -, e que o respeito mútuo com nossos pares apenas desenvolve-se numa idade ulterior. Se isto talvez for verdade para numerosos mandamentos que permaneceram incompreendidos, tal tese parece duvidosa no 
que se refere a fenômenos morais tão fundamentais como o senso de justiça, o respeito pelas promessas e a espera de que os pais respeitem, eles mesmos, as normas que impõem. (Tugendhat, 1998, p.288)

Com relação ao valor da teoria piagetiana, tal crítica pode ser considera duplamente injusta. Em primeiro lugar: como comentado acima, se Piaget destacou as relações de coação e obediência no cenário das relações sociais infantis, é porque pretendia sublinhar o fato de que o eixo central do desenvolvimento moral é a passagem da heteronomia para a autonomia. Em segundo lugar: como veremos mais abaixo falando de generosidade, Piaget não se furtou de comentar que a descentração psicológica responsável pela construção da autonomia deve-se a fatores que, justamente, são estranhos as relações de coação. Todavia, o que nos importa deixar claro aqui é que autores, como Tugendhat, têm chamado a atenção sobre a riqueza da vida moral da criança menor.

No campo da Psicologia Moral, pesquisas mais recentes têm mostrado que o ponto de vista de Tugendhat é plausível. Laupa e Turiel (1986) verificaram que crianças de pré-escola não pensam ser correto acatar ordens como 'roubar' e 'ferir', mesmo elas vindo de figuras de autoridades, como os pais. Nem tudo, portanto, no universo moral infantil parece ser obediência a fontes exteriores. Haveria uma certa precocidade genética na capacidade de avaliação do justo e do injusto decorrente, não de uma misteriosa predisposição para o bem, mas, por um lado, de uma capacidade precoce de abstração de regras necessárias à mínima harmonia das relações interpessoais e, por outro, de uma sensibilidade, também precoce, ao bem estar alheio (Hoffman, 1978; La Taille, 2002c). Para designar estas características infantis, insuspeitas se a virmos apenas como 'ser obediente', Turiel (1983, 1993) elaborou a hipótese de que as crianças cedo identificam e diferenciam os Domínios Moral, Convencional e Pessoal, universalizando a legitimidade e a obrigatoriedade das regras pertencentes ao primeiro.

Como acontece com todas as teorias e dados empíricos oriundos das reflexões psicológicas- e talvez mais ainda no campo da Psicologia Moral- as teses de Turiel foram e são constestadas. Elas podem ser contestadas tanto no âmbito da oposição entre as abordagens universalistas e relativistas quanto no campo empírico (ver Biaggio, 1999). A primeira hipótese que vamos assumir no presente artigo é que $o$ universo moral da criança pequena não se resume a uma moral da obediência, nem à predominância de tendências hedonistas. Concordamos, portanto, com Tugendhat e Turiel no que diz respeito à riqueza do referido universo. Porém, diferentemente deles, destacamos a generosidade como virtude dominante, em fase de despertar do senso moral.

b) Um possível problema na conceituação do Domínio Moral, e, consequentemente, das pesquisas que visam avaliar seu destaque na moralidade infantil, é sua definição essencialmente a partir da noção de direitos. Com efeito, para verificar se as crianças pequenas distinguem este domínio, costuma-se lhes perguntar o que pensam de atos como 'ferir', 'bater', 'roubar', etc. Ora, vimos que a generosidade diferencia-se pelo fato de ela não contemplar direitos, mas sim necessidades. Mas cabe a generosidade no Domínio Moral? Não será ela do Domínio Pessoal? A resposta não é evidente. Por um lado, por ser altruísta e implicar o bem para outra pessoa, a generosidade cabe perfeitamente no Domínio Moral, como vimos acima. Mas, por outro, por ela não corresponder a uma exigência social, como também já analisamos, ela também cabe no Domínio Pessoal, pelo menos no que tange a uma característica essencial deste: a liberdade de escolha atestada socialmente. Em estudos mais recentes, Nucci (2000) admite sobreposições dos três Domínios, e sem dúvida este é o caso dos Domínios Moral e Pessoal quando se trata da generosidade. Portanto, podemos legitimamente fazer a hipótese de que a generosidade é uma virtude relevante do Domínio Moral das crianças menores. As análises e dados levantados no item 2 dotam esta hipótese de plausabilidade. Se houver duas éticas, uma da justiça e outra do cuidado, e se a predominância de uma sobre a outra depende da qualidade das primeiras interações criança/pais e criança/mãe (Gilligan, 1982), não se vê porque a ética do cuidado (que remete em parte à generosidade) não teria suas primeiras raízes na pequena infância. Vimos também que Eisenberg afirma que as atitudes pró-sociais, que também remetem em parte à generosidade, são mais precoces que aquelas baseadas na justiça, por serem menos dependentes de mandamentos adultos e pouco balizáveis por regras. Finalmente vimos que Hoffman considera a empatia, sentimento necessário à generosidade, precoce.

c) Todavia, não fazemos apenas a hipótese de que a generosidade está presente no universo moral infantil, mas também de que ela é melhor assimilada e, portanto, integrada à consciência moral do que a justiça. Vejamos as razões que nos levam a considerar esta hipótese.

Em primeiro lugar, devemos lembrar que a justiça, que implica equilíbrio entre direitos e deveres, pressupõe relações de reciprocidade e o conceito de igualdade (também o de eqüidade, num nível superior). Ora, como poderiam crianças pré-operatórias conceber por inteiro tal virtude, se justamente lhes faltam as operações mentais necessárias para pensar o mundo social pela reciprocidade e a igualdade. As descrições do universo moral da pequena infância feitas por Piaget e Kohlberg são coerentes com a leitura que fazem do desenvolvimento cognitivo. Como então interpretar os dados colhidos por Turiel (1993), admitindo que sejam de fato representativos da fase do despertar do senso moral na criança? A questão é difícil e controversa. Pode-se levantar a hipótese de que o reconhecimento da dor alheia leve os sujeitos a condenar os atos de agressão. Com efeito, os exemplos do Domínio Moral sempre tratam de formas de agressão, e a simpatia pela vítima pode bastar para levar à condenação categórica de tais atos, sem que uma operação de reciprocidade seja necessária. Tratar-se-ia mais de simpatia do que de conceito de justiça. A generosidade, quanto a ela, não pressupõe nem igualdade nem reciprocidade, e como também pertence ao Domínio Moral, 
faz sentido pensar que seja presente no universo moral das crianças menores e que, inclusive, motive as crianças a condenar diversas formas de agressão.

Em segundo lugar, lembremos que a simpatia corresponde a uma capacidade emocional precoce, e como a generosidade tem íntima relação com ela, sua presença e força precoces no desenvolvimento moral não podem ser descartadas.

Em terceiro e último lugar, no seio da própria teoria piagetiana, a generosidade não é esquecida enquanto componente importante, no processo de descentração que leva a colocar a justiça no centro do universo moral. Eis o que escreveu Piaget: É quando a criança habitua-se a agir do ponto de vista dos próximos, epreocupa-se mais em corresponder aos anseios dos outros do que a eles obedecer, que ela chega a julgar em função das intenções (Piaget, 1932/1992, p.105). Sabe-se que a capacidade de julgar em função das intenções é um traço característico da autonomia moral, assim como definida por Piaget, e, portanto, capacidade contemporânea da prevalência da justiça sobre a obediência. Na citação que acabamos de transcrever, fica clara a tese piagetiana segundo a qual um dos fatores que leva uma criança pequena a desenvolver-se moralmente é sua capacidade e motivação em corresponder às expectativas singulares das pessoas de seu entorno. Eis exatamente o que se faz nos atos generosos. É possível re-escrever a citação de Piaget da seguinte forma: os atos generosos das criança menores testemunham de sua capacidade e vontade de levar em conta o ponto de vista alheio (descentração) e, logo, abrem o caminho para as relações de reciprocidade sobre as quais repousam os ideais de justiça. Em resumo, pelo fato de a generosidade não pressupor reciprocidade e igualdade, pelo fato de estar relacionada à capacicade de simpatia, e pelo fato de ela ser um elemento desencadeador de progressivas descentrações, tal virtude deve ocupar um lugar de destaque no universo moral da criança pré-operatória e ser melhor assimilada que as demais, entre as quais a justiça.

Mas como aquilatar este suposto lugar da generosidade no universo moral da pequena infância? Nossa opção recai sobre os estudos dedicados aos sentimentos morais.

d) São conhecidos os estudos sobre o tema batizado de 'happy victimiser' (ver Arsenio \& Lover, 1996, para uma revisão das pesquisas realizadas sobre este tema). Eles evidenciaram que as crianças pré-operatórias atribuem sentimentos positivos (Ex.: satisfação) a agressores, ou seja, àqueles que transgridem regras que proíbem causar algum dano a alguém, atribuição esta que desaparece por volta dos nove anos de idade, sendo substituída por atribuição de sentimentos negativos (Ex.: vergonha). Faz todo sentido a indagação de Lourenço (1997): por que, se Turiel tiver razão, as crianças menores não têm a moralidade emocional à altura da sofisticação de seus juízos?. Acrescenta ele que os dados encontrados são mais coerentes com a teoria de Kohlberg.

Qual o significado psicológico destes dados? Se eles forem interpretados de um ponto de vista exclusivamente cognitivo- como, por exemplo, pensar que traduzem a dificuldade de as crianças menores assimilarem o fato de que as ações humanas nem sempre são coerentes com os sentimentos - eles apresentam pouco interesse para a Psicologia Moral. Em compensação, se avaliarmos que traduzem a articulação entre juízo moral e sentimentos morais, eles são do maior interesse. E é evidentemente esta a perspectiva de análise daqueles que pesquisaram os relatos infantis e adolescentes sobre este tipo de sentimento. São incapazes as crianças menores de experimentar remorso, culpa, vergonha e outros sentimentos relacionados ao 'agir de forma errada'? A rigor, nunca saberemos ao certo, pois sempre dependemos de relatos verbais, que, eles mesmos, podem não ser fidedignos. Mas o fato é que se encontram diferenças genéticas notáveis quanto as estes relatos, sejam eles referentes a sentimentos negativos vagos (como 'sentirse mal', ver Arseni, 1996; Lourenço, 1997; Nunner-Winkler \& Sodian, 1988), ou a sentimentos precisamente nomeados, como a vergonha (La Taille, 2002a,2002b). A interpretação que nos parece a mais adequada incide sobre o conceito de heteronomia.

Piaget sublinhou freqüentemente que, nas relações assimétricas de autoridade (coação), as noções e regras são assimiladas superficialmente pelo pólo dominado. Piaget (1954) empregou a expressão francesa de 'plaqué sur la conscience' para falar do fenômeno: as noções e regras pouco penetram na consciência e, portanto, não configuram novas estruturas, novas redes de significados. Em uma palavra, ficam isoladas. Em compensação, as relações de reciprocidade (cooperação) promovem o enraizamento das noções (que se tornam conceitos, na terminologia piagetiana) e das regras (que passam a ser entendidas por intermédio de seu 'espírito') na consciência, fato que não somente permite uma rica assimilação das mesmas, como sua articulação em redes de significado mais amplas. Isto explicaria porque a criança menor, ainda submetida a relações coercitivas, não articularia a dimensão judicativa das transgressões e a dimensão afetiva. Já em fase de autonomia, tal articulação aconteceria.

Voltemos então ao argumento de Lourenço, que vê contradição entre as afirmações de Turiel a respeito da riqueza do universo moral infantil e as atribuições de sentimentos positivos a agressores. Como pode uma criança, do ponto de vista judicativo, pregar a legitimidade universal de determinadas regras, e ainda negar o fato de que sua transgressão pode causar sentimentos negativos? A interpretação que damos deste fato é a que segue. Colocamos acima que a condenação precoce de atos que ferem direitos alheios, portanto, de atos injustos, pode ser explicada pelo sentimento de simpatia. Porém, como as regras que proíbem tais atos também provém de figuras de autoridade, temos que as primeiras noções de justiça têm duas fontes diferentes. Temos também que, quando os sujeitos devem avaliar os sentimentos de um transgressor, pensam, por um lado, no sentimento negativo da vítima (todos os sujeitos inferem a tristeza da vítima, ver Arsenio, 1996) e por outro, na desobediência a uma autoridade. Ora, tudo leva a crer que, neste caso, domina a dimensão heterônoma, com as conseqüências já apontadas. Mas imaginemos que a 'agressão' não tenha sido fruto de uma transgressão 
voluntária, mas sim de uma ação não intencional. Imaginemos, portanto, que seja retirada a dimensão heterônoma da obediência e perguntemo-nos se as crianças menores ainda vão atribuir sentimentos positivos ao responsável por danos a outrem. Nunner-Winkler, e Sodian (1988) debruçaram-se sobre esta questão e encontraram que, neste caso, as crianças menores atribuem sentimentos negativos ao agressor involuntário. Logo, parece que obedecer ou desobedecer permanece critério central no universo das crianças menores, fato que é coerente com a abordagem teórica de Piaget e Kohlberg.

Quanto à generosidade, sendo ela relacionada à empatia, pouco regrada e pouco imposta por autoridade, e, como escreve Piaget, desencadeadora espontânea de descentrações que levam à reciprocidade, faz todo sentido fazer a hipótese de que as crianças menores atribuirão sentimentos negativos a pessoas que agem de maneira não generosa. As duas pesquisas que agora passamos a descrever procuram testar esta hipótese. Se confirmada, as análises que fizemos da generosidade (os sub-itens a, b, e c) sairão fortalecidas.

\section{Método}

Realizamos duas pesquisas (Estudo 1 e Estudo 2). Na primeira, verificamos se crianças de 6 e 9 anos atribuem sentimentos positivos ou negativos a uma personagem que não foi generosa, fazendo a hipótese de que as crianças menores não atribuiriam sentimento positivo a tal personagem. $\mathrm{Na}$ segunda, submetemos outros sujeitos das mesmas faixas etárias a duas situações, uma envolvendo injustiça, outra conduta não generosa (idêntica à do Estudo 1), para verificarmos se há diferenças nas atribuições de sentimentos experimentados pelo agressor e pela personagem não generosa. Para este Estudo, fizemos a hipótese de que os sujeitos de 6 anos atribuiriam sentimento positivo ao injusto, mas não à personagem não generosa, enquanto os sujeitos de 9 anos não atribuiriam sentimento positivo em ambos os casos. Vamos agora descrever os dois Estudos e apresentar os resultados obtidos.

\section{Estudo 1}

Nossa amostra foi composta de 30 participantes de 6 anos e 32 de 9 anos, alunos de uma escola particular da cidade de São Paulo (Escola A). A eles foi contada a seguinte história (História 1 - não generosidade):

História 1: Paulo e Márcio são vizinhos e costumam brincar juntos Um dia, Paulo ficou doente e estava muito triste porque não poderia sair de casa. Então, Paulo pediu a seu amigo Márcio que fosse até sua casa para que pudessem brincar. Márcio não estava com vontade e não foi.

Após nos certificarmos da compreensão da história, fizemos a nossos sujeitos as seguintes perguntas:

1) Márcio agiu certo?

2) Como Márcio se sentiu?

\section{Estudo 2}

Nossa amostra foi composta de 32 participantes de 6 anos e 36 de 9 anos, alunos de uma outra escola particular da cidade de São Paulo (Escola B). Com eles foi, num primeiro momento, replicado o Estudo 1. Em seguida, ouviram a História 2 (não justiça).

História 2: Um dia, a professora de Alice distribuiu massinha de modelar para os alunos e pediu que fizessem algo. Alice e mais duas amigas resolveram fazer uma casinha. O combinado era deixar a casinha na escola, pois era das três. Quando ficou pronta, Alice achou muito bonita e acabou levando-a para sua casa.

Após nos certificarmos da compreensão da história, fizemos a nossos sujeitos as seguintes perguntas:

1) Alice agiu certo?

2) Como Alice se sentiu?

\section{Resultados}

\section{Estudo 1}

O resultados obtidos para as perguntas encontram-se na Tabela 1. Verifica-se que não se encontra gênese na atribuição de sentimento negativos $\left(\mathrm{c}^{2}=4,43\right.$; $\left.p=\mathrm{ns}, g l=1\right)$.

\section{Estudo 2}

A Tabela 1 apresenta também as repostas dadas à História 1 (não generosidade). Verifica-se que não se encontra gênese na atribuição de sentimento negativos $(\mathrm{c} 2=0,041 ; p=\mathrm{ns}$, $g l=1$ ). Ainda na Tabela 1, encontram-se as respostas dadas para a História 2 (não justiça). A atribuição de sentimento positivo decai de $71,87 \%$ aos 6 anos para $11,11 \%$ aos 9 anos, diferença estatisticamente significativa $\left(\mathrm{c}^{2}=16,74 ; p<0,001\right.$; $g l=1)$.

\section{Discussão}

Antes de mais nada, vamos sublinhar o fato de que a maioria de nossos participantes dos 2 estudos (ver a Tabela 1) condena tanto a falta de generosidade (História 1) quanto $\mathrm{o}$ ato injusto (História 2). A diferença significativa aparece quando da atribuição de sentimentos positivos ou negativos a ambos os protagonistas.

Os resultados obtidos em relação ao 'vitimizador feliz' -, ou seja aquele que transgride uma norma e assim fere um direito alheio (no caso, direito ao usufruto da propriedade, uma vez que a personagem Alice guarda para si o que é de seu grupo)- são coerentes com o que os estudos anteriores já citados encontraram (ver Tabela 1).

Em compensação, tal gênese não se encontra nas atribuições de sentimentos positivos à personagem não generosa. No Estudo 1, apenas um participante de 6 anos e 2 de 9 anos fazem esta atribuição (ver Tabela 1), e no Estudo 2 (com outros participantes), apenas 4 de cada faixa etária. Quanto à atribuição de sentimento negativo, tampouco encontramos gênese. No Estudo 1, temos 53,3\% dos participantes de 6 anos e 53,1\% dos de 9 anos que atribuem 
Tabela 1

Respostas dos Participantes dos Estudos 1 e 2 às Perguntas "Mário Agiu Certo?" e "Como Mário se sentiu" e dos Participantes do Estudo 2 às Perguntas "Alice Agiu Certo" e "Como Alice se Sentiu"

\begin{tabular}{|c|c|c|c|c|}
\hline & \multicolumn{2}{|c|}{ Estudo 1} & \multicolumn{2}{|c|}{ Estudo 2} \\
\hline & 6 anos $(n=30)$ & $9 \operatorname{anos}(n=32)$ & $6 \operatorname{anos}(n=32)$ & $9 \operatorname{anos}(n=36)$ \\
\hline \multicolumn{5}{|c|}{ Resposta à Pergunta 'Mário Agiu Certo?' } \\
\hline agiu errado & $93,3 \%(n=28)$ & $71,9 \%(n=23)$ & $81,25 \%(n=26)$ & $86,11 \%(n=31)$ \\
\hline agiu certo & $3,3 \%(n=1)$ & $12,5 \%(n=4)$ & $15,62 \%(n=5)$ & $5,55 \%(n=2)$ \\
\hline não sei & $3,3 \%(n=1)$ & $12,5 \%(n=4)$ & $3,3,1 \%(n=1)$ & $8,32 \%(n=3)$ \\
\hline \multicolumn{5}{|c|}{ Resposta à Pergunta 'Como Mário se Sentiu?' } \\
\hline $\begin{array}{l}\text { sentimento } \\
\text { negativo }\end{array}$ & $53,3 \%(n=16)$ & $53,1 \%(n=17)$ & $84,37 \%(n=27)$ & $86,111 \%(n=31)$ \\
\hline $\begin{array}{l}\text { sentimento } \\
\text { positivo }\end{array}$ & $3,3 \%(n=1)$ & $6,2 \%(n=2)$ & $12,5 \%(n=4)$ & $11,11 \%(n=4)$ \\
\hline indiferença & $6,7 \%(n=2)$ & $9,4 \%(n=3)$ & - & - \\
\hline não sei & $36,7 \%(n=11)$ & $31,25 \%(n=10)$ & $3,12 \%(n=1)$ & $2,77 \%(n=1)$ \\
\hline \multicolumn{5}{|c|}{ Resposta à Pergunta 'Alice agiu certo?' } \\
\hline agiu errado & & & $96,87 \%(n=31)$ & $97,23 \%(n=35)$ \\
\hline agiu certo & & & $3,15 \%(n=1)$ & $12,5 \%(n=1)$ \\
\hline não sei & & & $0 \%$ & $0 \%$ \\
\hline \multicolumn{5}{|c|}{ Resposta à Pergunta 'Como Alice se Sentiu? } \\
\hline $\begin{array}{l}\text { sentimento } \\
\text { negativo }\end{array}$ & & & $28,12 \%(n=9)$ & $55,55 \%(n=20)$ \\
\hline $\begin{array}{l}\text { sentimento } \\
\text { positivo }\end{array}$ & & & $71,875 \%(n=23)$ & $11,11 \%(n=4)$ \\
\hline não sei & & & $0 \%$ & $33,33 \%(n=12)$ \\
\hline
\end{tabular}

sentimento negativo, e no Estudo 2, o número de participantes que faz tal atribuição é ainda maior $(84,37 \%$ dos de 6 anos e $86,11 \%$ dos de 9 anos), fato que também não configura gênese.

Em suma, podemos afirmar que nossos dados mostram que: 1) crianças de 6 anos, em sua grande maioria, não atribuem sentimentos positivos a quem falta com a generosidade, mas o fazem quando se trata de ato injusto, 2) as crianças de 6 anos atribuem sentimentos negativos aos não generosos tanto quanto crianças de 9 anos. Portanto a presente pesquisa leva a crer que, diferentemente da justiça, a generosidade ocupa lugar diferenciado no universo moral das crianças menores. À luz destes dados, e para finalizamos o presente texto, vamos retomar duas hipóteses de psicologia genética apresentadas no item 3.

A primeira delas era: a generosidade é virtude presente no início da gênese da moralidade. Para elaborá-la, começamos por defender, através de revisão de literatura psicológica, que nem tudo é relação com autoridade, hedonismo instrumental e medo do castigo, no início da vida moral infantil, e, em seguida, destacamos a importância da generosidade. Nossos dados dão verossimilhança à nossa hipótese. Por um lado, a quase totalidade das crianças de 6 anos condena a atitude não generosa. Por outro, já concebe o desconforto experimentado pela personagem não generosa. Logo, não vemos como pensar que a referida virtude não seja um tema do universo moral infantil.

Nossa segunda hipótese vai mais longe: a generosidade não somente é virtude presente no inúcio da gênese da moralidade, comoé melhor assimilada e, portanto, integrada à consciência moral, do que a justiça nesta mesma fase de desenvolvimento. Aqui, são os dados sobre atribuição de sentimentos que parecem decisivos. Com efeito, como explicar o fato de crianças da mesma faixa etária, 6 anos, pensarem que quem fere um direito alheio sente-se 'bem' e que quem falta com a generosidade sentese 'mal'? Em ambos os casos, os protagonistas agiram por interesse egoísta. Não é portanto este o diferencial entre as duas situações. Em ambos os casos há uma pena causada a um terceiro. Logo, também não reside neste ponto a diferença entre as duas histórias contadas. A diferença deve estar no fato de a generosidade, por ser menos relacionada às imposições das figuras de autoridade do que as regras de justiça, e mais a relações sociais simétricas despertadas pela simpatia, ser produto de uma construção mais autêntica porque, decorrente de relações de cooperação.

Somente falta avaliar a relevância de nossas reflexões e dados para a Psicologia do Desenvolvimento Moral:

1) Para compreender tal desenvolvimento, notadamente no seu início, deve-se levar em conta o sentimento de simpatia, que certamente precede os de culpa e vergonha (Hoffman, 1978; La Taille, 2002c); 
2) Os deveres ditos positivos, que presidem as condutas chamadas de pró-sociais e que são pouco normatizados, fazem parte das inquietações morais infantis, assim como o concebe Eisenberg;

3) A teoria de Kohlberg, que prevê um início de desenvolvimento moral restrito ao egoísmo, ao medo do castigo e à referência à autoridade deve ser revista, ou melhor, ampliada. Nossos dados em nada levam a contestar que tais sejam características das crianças menores, mas mostram que há mais elementos, e que estes são mais positivos e coerentes com o desenvolvimento posterior da moralidade infantil; e,

4) A afirmação acima nos leva de volta à abordagem piagetiana. Se Piaget enfatizou a heteronomia das crianças menores, é que estava preocupado com o ‘sujeito ético’ cujo desenvolvimento crucial implica a superação da moral da obediência para uma moral da cooperação. Porém, verificase em vários trechos de sua obra Le Jugement Moral chez l'Enfant que ele estava atento à riqueza do 'sujeito moral' infantil, identificando a vontade de corresponder aos anseios alheios como motor das descentrações necessárias à vitória do ideal de justiça sobre a submissão à autoridade. Nossos dados lhe dão razão.

Ao propor que se leve em conta a generosidade, para compreender a moralidade, estaremos concebendo o ser humano como um 'saco de virtudes'? De modo algum. Uma teoria do 'saco de virtudes' pressupões justaposição entre diversas virtudes. Quanto a nós, propomos uma integração entre elas, e no presente texto explicitamos a importância da generosidade como 'motor' do desenvolvimento moral cujo eixo é a justiça, a mais racional de todas as virtudes, como dizia Piaget, e aquela sem a qual uma sociedade se destrói, como pensava Adam Smith.

\section{Referências}

Aristoteles (1965). Ethique de Nicomade. Paris: Flamarion. (Original s.d.)

Arsenio, W. \& Lover, A. (1996). Children's conception os socioimoral affecte: Happy victimizers, mixed emotions, and other expentancies. In M. Killen \& D. Hart (Eds.), Morality in everyday life (pp.87128). Cambridge: Cambridge University Press.

Biaggio, A.M.B. (1999). Universalismo versus relativismo no julgamento moral. Psicologia: Reflexão \&̊ Crítica, 12, 5-19.

Comte-Sponville, A. (1995). Petit traité des grandes vertus. Paris: PUF.

Dias, A.C.F. (2002). Estudo psicológico sobre o lugar das virtudes no universo moral aos 7 anos de idade: As crianças da primeira série discutem coragem e generosidade. Dissertação de Mestrado nãopublicada, Curso de Pós-Graduação em Psicologia Escolar e do Desenvolvimento Humano, Instituto de Psicologia, Universidade de São Paulo. São Paulo: SP.

Eisenberg-Berg, N. (1979). Developpment of chidren's prosocial judgment. Developmental Psychology, 15, 129-137.

Eisenberg, N. \& Miller, P.A. (1987). The relationship of empathy to prosocial and related behaviors. Psychological Bulletin, 101, 91-119.

Eisenberg, N., Lennon, R., \& Roth, K. (1983). Prosocial development: A longitudinal study. Developmental Psychology, $19,846-855$.
Flanagan, O. (1996). Psychologie morale et éthique. Paris: PUF.

Freud, S. (1991). Le moi et le ça. Paris: PUF. (Original publicado em 1922)

Gilligan, C. (1982). Uma voz diferente. Rio de Janeiro: Rosa dos Ventos.

Gilligan, C. (1988). Remaping the moral domain: New images of self and relationship. In C. Gilligan (Ed.), The moral domain (pp.3-20). Boston, MA: Havard University Press.

Hoffman, M. (1978). Desenvolvimento moral. In P.H. Mussen (Ed.), Psicologia da criança: socialização (Coleção Carmichael, pp.1170). São Paulo: EDUSP.

Kahn, P.H. (1992). Chidren's obligatory and discretionary moral judgments. Child Developpment, 63, 416-430.

Kant, E. (1994). Métaphysique des moeurs, première partie. Paris: Flamarion. (Original publicado em 1785)

Kohlberg, L. (1981/1984/ 1987). Essays on moral development. San Francisco, CA: Harper \& Row.

La Taille, Y. de (2002a). Vergonha, a ferida moral. Petrópolis, RJ:Vozes.

La Taille, Y. de (2002b). O sentimento de vergonha e suas relações com a moralidade. Psicologia: Reflexão \& Crítica, 15, 13-25.

La Taille, Y. de (2002c). Cognição, afeto e moralidade. In M.K. Oliveira, D.T.R. Souza, \& M.C. Rego (Eds.), Psicologia, educação e as temáticas da vida contemporânea (pp.135-158). São Paulo: Moderna.

Laupa, M. \& Turiel, E. (1986). Children'a conceptions of adult and peer authority. Child Development, 57, 405-412.

Lima, V. (2003). A generosidade segundo sujeitos de 6, 9 e 12 anos. In R. Ribeiro, M. Nenevê, \& M. Proença (Eds.), Psicologia e saúde na Amazônia: Pesquisa e realidade brasileira (pp. 15-38). São Paulo: Casa do Psicólogo.

Lourenço, O. (1997). Children's attribution of moral emotions to victimizers: Some data, doubts ans suggestions. British Journal on Development Psychology, 15, 425-438.

MacIntyre, A. (1997). Après la vertu. Paris: PUF.

Nucci, L. (2000). Psicologia moral e educação: Para além de crianças boazinhas. Educação e Pesquisa, 26, 71-90.

Nunner-Winkler, G. \& Sodian, B. (1988). Children's understanding of moral emotions. Child Development, 59, 1323-1338.

Piaget, J. (1954). Les relations entre l'affectivité et l'intelligence. Paris: Sorbonne.

Piaget, J. (1992). Le Jugement Moral chez l'Enfant. Paris: PUF. (Original publicado em 1932)

Ricoeur, P. (1990). Soi-même comme un autre. Paris: Seuil.

Savater, F. (2000). Ética como amor próprio. São Paulo: Martins Fontes.

Schopenhauer, A. (1995). Sobre o fundamento da moral. São Paulo: Martins Fontes. (Original publicado em 1840)

Smith, A. (1999). Théorie des sentimentos moraux. Paris: PUF. (Original publicado em 1723)

Spaemann, R. (1997). Bonheur et bienveillance. Paris: PUF.

Tognetta, L.R.P. (2003). A construção da solidariedade e a educação do sentimento na escola. Campinas: FAPESP \& Mercado de Letras.

Tugendhat, E. (1998). Conférences sur l'éthique. Paris: PUF.

Turiel, E. (1983). The development of social knowledge: Morality and convention. Cambridge: Cambridge University Press.

Turiel, E. (1993). Nature et fondement du raisonnement social dans l'enfance. In P. Changeux (Ed.), Les fondements naturels de l'éthique (pp.301-318). Paris: Odile Jacob. 